\title{
Three-dimensional characteristics of Fe-rich intermetallics in gravity-cast Al-6Si alloys
}

\author{
Chen Hu, Wen-feng Luo and *Hai-dong Zhao \\ National Engineering Center for Metallic Materials Net-shape Forming, South China University of Technology, Guangzhou 510640, China
}

\begin{abstract}
Fe-rich intermetallics, especially $\beta$-Fe phase, usually forming in the microstructure of cast aluminum alloys, are very detrimental to mechanical properties. In the present work, the effects of Fe content on phase transformation and microstructures were analyzed using a 3D X-ray microscope. Based on the highresolution 3D X-ray computed tomography, the 3D characteristics of Fe-rich intermetallics and micropores in the gravity-cast Al-6Si alloys with different Fe contents were investigated. In addition, the effect of intermetallics on the microporosity was discussed. The results show that with increasing the $\mathrm{Fe}$ content from $0.10 \mathrm{wt} . \%$ to $0.60 \mathrm{wt} . \%$, the volume fraction of Fe-rich intermetallics and the volume of the largest size Fe-rich intermetallic increased, and the 3D morphology of intermetallics changed from fine flake to network aggregation. As the Fe contents increased, the shrinkage pores were characterized, which were rather complex due to the micropores promoted by the intermetallics interactions.
\end{abstract}

Key words: Fe-rich intermetallics; 3D X-ray computed tomography; micropores; Al-Si alloy

CLC numbers: TP391.99_Document code: A Article ID: 1672-6421 2017)05-379-07

\begin{abstract}
A luminum alloys have the advantages of low density, high specific strength and good corrosion resistance etc, which are widely used in recent years. Due to the resource recycle requirement, aluminum alloy castings are mostly produced using low-cost recycled materials. However, recycled materials with a high $\mathrm{Fe}$ content can result in Fe-rich intermetallics in the castings. $\beta$-Fe phases, as common Fe-rich intermetallics, can cause stress concentration and reduce the casting strength and ductility. They also promote the formation of micropores. Puncreobutr et al. ${ }^{[1]}$ observed the growth of $\beta$-Fe intermetallic using a real-time synchrotron radiation $\mathrm{X}$ ray technique; they found three kinds of nucleation sites of $\beta$-Fe intermetallic, i.e., oxide film, near $\alpha$-Al dendritic surface, and melt center. Wang et al. ${ }^{[2]}$ pointed out that the $\beta$-Fe intermetallic growth process was mainly composed of three stages: lateral growth, attachment and diffusion control growth, and ladder growth from a two-dimensional angle by synchrotron
\end{abstract}

\section{*Hai-dong Zhao}

Male, born in 1970, Professor. Research interests: Al casting processing and its numerical simulation.

E-mail: hdzhao@scut.edu.cn

Received: 2017-08-15; Accepted: 2017-09-14 radiation X-ray real time observation in the Al-7.5Si$3.5 \mathrm{Cu}-0.8 \mathrm{Fe}$ alloy. Terzi et al. ${ }^{[3]}$ observed the growth of $\beta$-Fe intermetallic in the $\mathrm{Al}-8 \mathrm{Si}-4 \mathrm{Cu}-0.8 \mathrm{Fe}$ alloy, and found the $\beta-\mathrm{Fe}$ intermetallic branching during growth. In addition, researchers found that Fe-rich intermetallics have an important effect on micropores ${ }^{[4-9]}$.

In this study, with the high-resolution 3D X-ray computed tomography, the Fe-rich intermetallics in the gravity-cast Al-6Si alloys with different Fe contents were investigated. In addition, the influence of the intermetallics on the micropores was also discussed.

\section{Experimental procedure}

In this experiment, pure aluminum (99.95\%), Al$20 \mathrm{Si}$ alloys, and $\mathrm{Al}-20 \mathrm{Fe}$ alloys were used as the raw materials. The Fe content was set to $0.1 \mathrm{wt} . \%, 0.35 \mathrm{wt} . \%$ and $0.6 \mathrm{wt} . \%$ by changing the addition of $\mathrm{Al}-20 \mathrm{Fe}$ alloy. The chemical compositions of alloy are listed in Table 1. Al-6Si alloy wedge castings were used as the research object, as shown in Fig. 1. 
Table 1: Chemical compositions of Al-6Si-xFe alloys (wt.\%)

\begin{tabular}{|cccccccc} 
Alloy & Si & Fe & Mg & Mn & Ti & Al \\
\hline $10 \mathrm{Fe}$ & 6.44 & 0.104 & 0.00069 & 0.00129 & 0.00269 & Bal. \\
\hline $35 \mathrm{Fe}$ & 6.06 & 0.375 & 0.00077 & 0.00233 & 0.00259 & Bal. \\
$60 \mathrm{Fe}$ & 6.14 & 0.613 & 0.00084 & 0.00306 & 0.00269 & Bal.
\end{tabular}

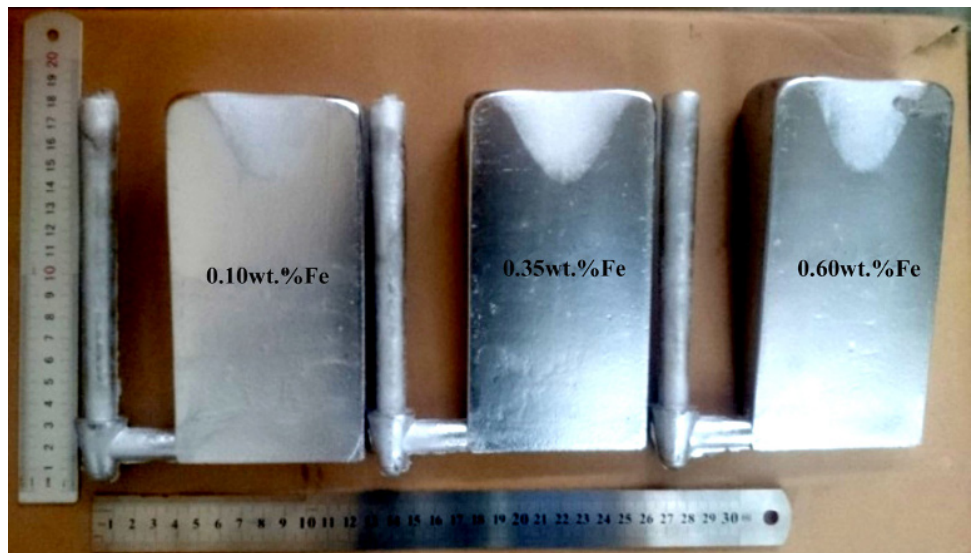

Fig. 1: Experimental wedge castings of $\mathrm{Al}-6 \mathrm{Si}-x \mathrm{Fe}(x=0.10,0.35$, and $0.60 \mathrm{wt} . \%$ ) alloys

Samples with a size of $1 \times 1 \times 10 \mathrm{~mm}^{3}$ were directly machined from the casting center for the $3 \mathrm{D}$ X-ray CT scanning using the 3D X-ray microscope nanoVoxel-2000 series (Tianjin Sanying Precision Instruments, Tianjin, China), in which the tube voltage of $70 \mathrm{kV}$ and cone beam current of $145 \mu \mathrm{A}$ were used. A $2048 \times 2048$ pixels CCD detector combined with a $20 \times$ objective lens was used to record the scan results. The samples were rotated at a speed of $0.5^{\circ} \cdot \mathrm{min}^{-1}$ covering $360^{\circ}$ and then sets of $2 \mathrm{D}$ radiographic projections were recorded about the absorptions of X-rays through the samples. The huge raw data of $\sim 1.0 \mu \mathrm{m}$ resolution provided the possibility to obtain the accurate intermetallics morphology. The Avizo V8.1 software was used to identify the intermetallics, and the Volume Graphics 2.0 was applied to the reconstruction of 3D morphology of the intermetallics and micropores.

\section{Results and discussion}

\subsection{Phase transformation during solidification}

According to the measured compositions, the phase transformation of the experimental alloys was calculated by Thermo-Calc. Figure 2 shows the phase transformation during solidification of the Al-6Si-xFe alloys. It can be seen that the alloy solidification process divides into three stages: primary transformation, binary eutectic transformation, and ternary eutectic transformation, as shown in Table 2 .

\subsection{Microstructure}

Figure 3 shows the BSED (Back-Scattered Electron Detector) photograph of the cast alloys. The Fe-rich phase morphology clearly reveals that the phase is $\beta-\mathrm{Fe}$, which is consistent with the results of the Thermo-Calc. From the BSED photograph, it can be seen that when the content of Fe is $0.10 \mathrm{wt} . \%$, the $\mathrm{Fe}$-rich intermetallics are scattered in the eutectic region among $\alpha$-Al grains, their sizes are very small; the length is about $15 \mu \mathrm{m}$ and the thickness is only 2-4 $\mu \mathrm{m}$. When the Fe content is increased to $0.35 \mathrm{wt} . \%$, the $\beta$-Fe intermetallics mainly distribute in the eutectic region, but their size increases to about $50 \mu \mathrm{m}$; and they become thicker. When the
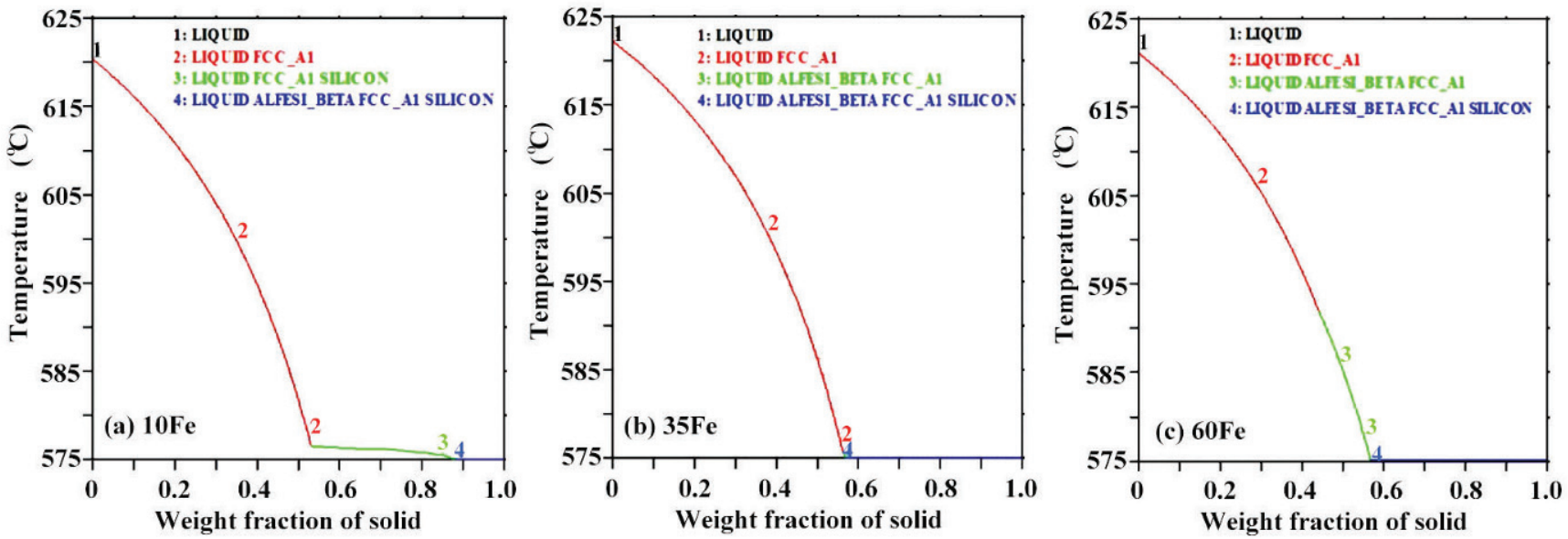

Fig. 2: Phase transformation during solidification of Al-6Si-xFe alloys 
Table 2: Reactions during solidification of Al-6Si-xFe alloys

\begin{tabular}{|c|c|c|c|}
\hline Solidification sequence & Reaction & Temperature $\left({ }^{\circ} \mathrm{C}\right)$ & Fraction of solid \\
\hline 1 & $\mathrm{~L} \rightarrow \mathrm{a}-\mathrm{Al}$ & $\sim 620$ & $0-0.58$ \\
\hline \multirow{2}{*}{2} & $L \rightarrow a-A l+S i(0.10 w t \% F e)$ & $577-575$ & $0.52-0.9$ \\
\hline & $\begin{array}{c}\mathrm{L} \rightarrow \mathrm{a}-\mathrm{Al}+\beta-\mathrm{Fe} \\
(0.35 w \mathrm{w} \% \% \mathrm{Fe} \text { and } 0.60 w t . \% \mathrm{Fe})\end{array}$ & $592-575$ & $0.45-0.57$ \\
\hline 3 & $\mathrm{~L} \rightarrow \alpha-\mathrm{Al}+\mathrm{Si}+\beta-\mathrm{Fe}$ & 575 & $\sim 1$ \\
\hline
\end{tabular}
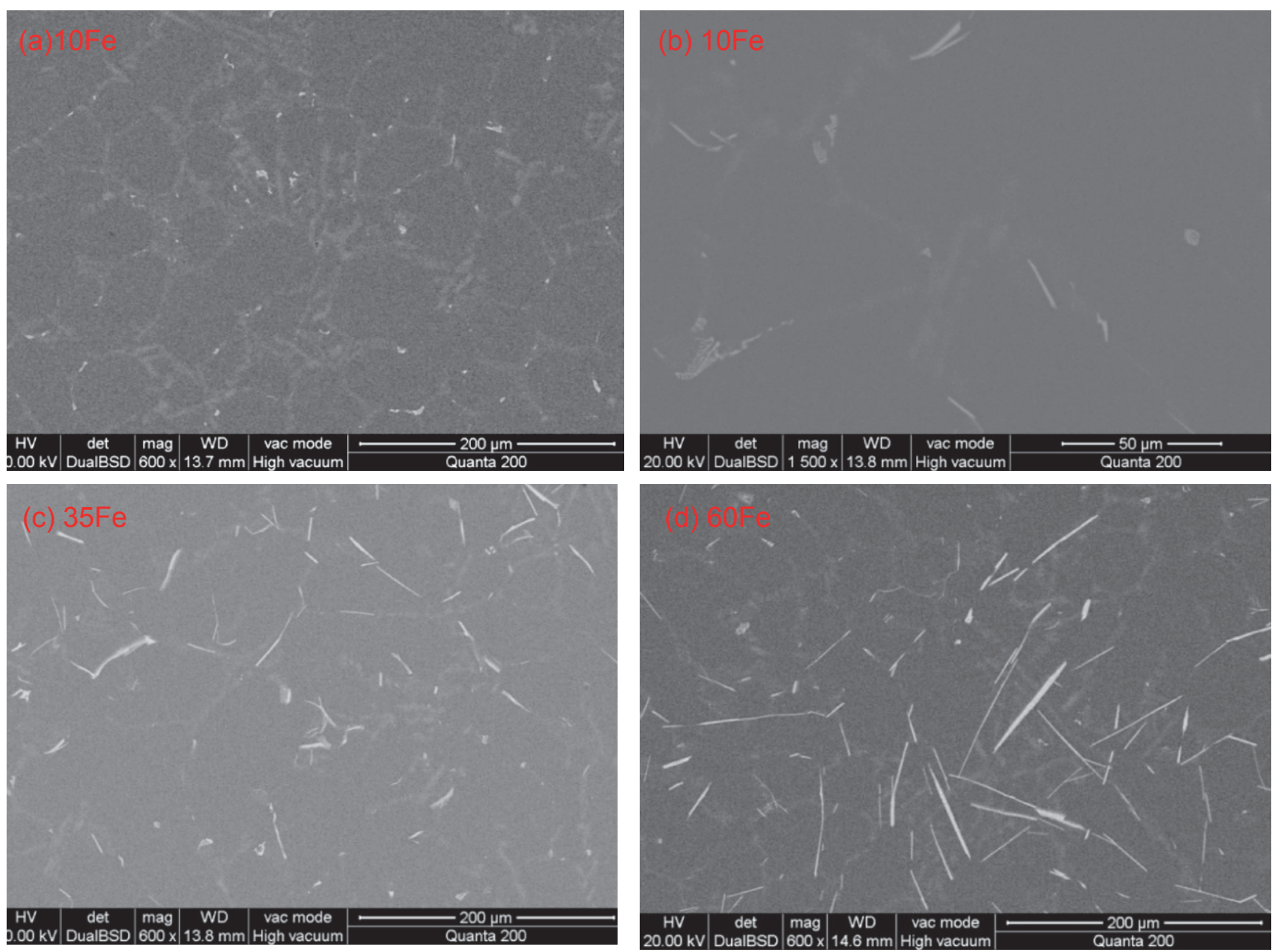

Fig. 3: Fe-rich intermetallics in Al-6Si-xFe alloys

content of $\mathrm{Fe}$ is $0.60 \mathrm{wt} . \%$, the intermetallics cross through the eutectic regions. They are $\sim 150 \mu \mathrm{m}$ in length and $\sim 12 \mu \mathrm{m}$ in thickness.

The morphology and distribution of the $\beta$-Fe intermetallics are related to the formation process. When the Fe content is low, $\beta$-Fe mainly forms during the three-phase eutectic reaction. Due to the limited liquid remaining and low Fe content, the formed $\beta-F e$ is small, as shown in Fig. 3(a) and (b). When the Fe content is increased to $0.60 \mathrm{wt} . \%, \beta$-Fe intermetallics nucleate and grow due to binary eutectic reaction. The high Fe content and long growth time result in the final large $\beta$-Fe intermetallics, as shown in Fig. 3(d).

\subsection{Three-dimensional characteristics of Fe- rich intermetallics}

As can be seen from Fig. 3(a), the $\beta$-Fe in the $10 \mathrm{Fe}$ is so small that it cannot be detected during the tomography. The results of the analysis do not contain the specimen of $10 \mathrm{Fe}$. After threedimensional X-ray tomography and reconstruction, the $\beta$-Fe morphology in the specimens of $35 \mathrm{Fe}$ and $60 \mathrm{Fe}$ is shown in Fig. 4. Table 3 shows the volume data of $\beta$-Fe in both specimens.

It can be seen from Table 3 that when the Fe content is increased from $0.35 \mathrm{wt} . \%$ to $0.60 \mathrm{wt} . \%$, the total volume of $\beta$-Fe is doubled; the volume of the largest size intermetallics increases by 23 times, the intermetallics number decreases by 


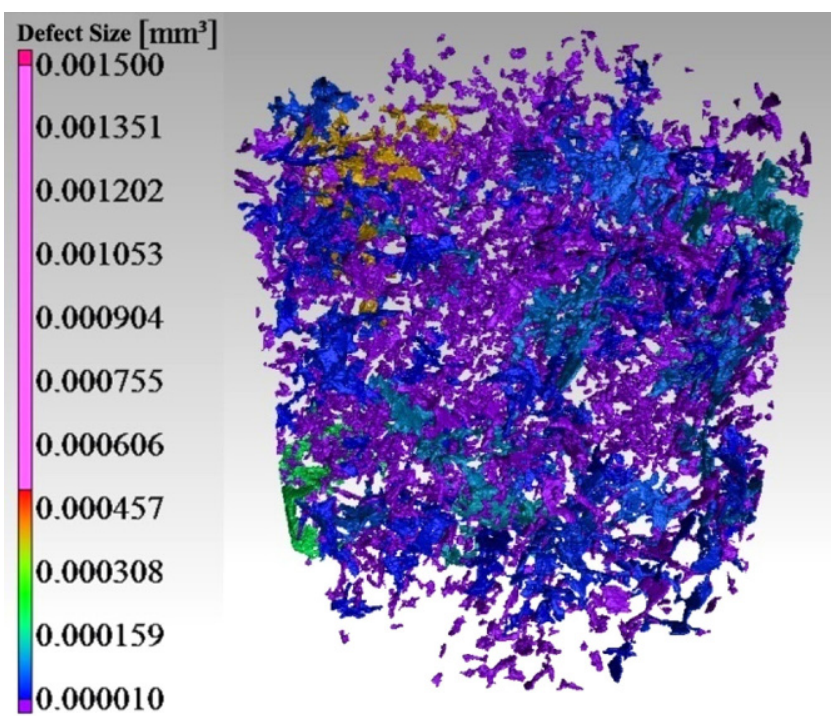

(a) $35 \mathrm{Fe}$

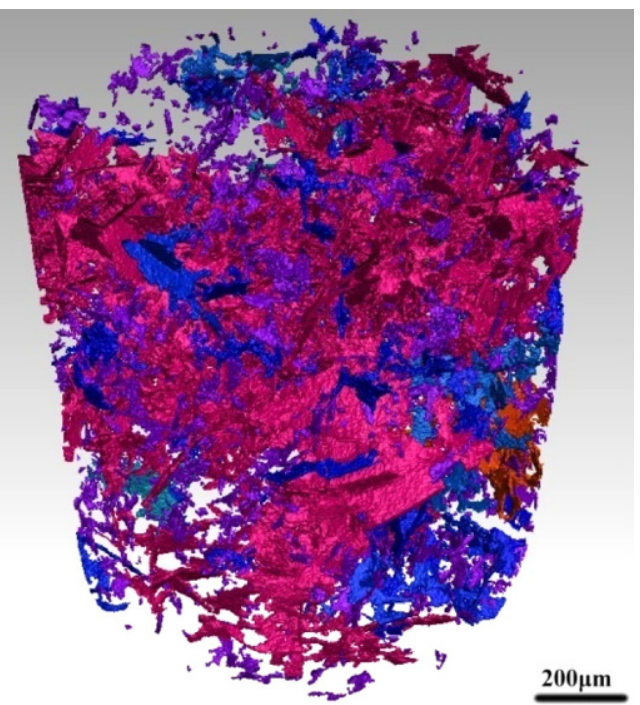

(b) $60 \mathrm{Fe}$

Fig. 4: 3D morphology of $\beta-\mathrm{Fe}$ intermetallics in 35Fe and 60Fe specimens

Table 3: Characteristics of $\beta-\mathrm{Fe}$ intermetallics in $35 \mathrm{Fe}$ and $60 \mathrm{Fe}$ specimens

$\begin{array}{ccccccc}\text { Sample } & \begin{array}{c}\text { Number of } \\ \text { intermetallics }\end{array} & \begin{array}{c}\text { Volume of } \\ \text { intermetallics } \\ \left(\mathbf{m m}^{3}\right)\end{array} & \begin{array}{c}\text { Volume of the } \\ \text { largest } \\ \text { intermetallics } \\ \left(\mathbf{m m}^{3}\right)\end{array} & \begin{array}{c}\text { Volume of } \\ \text { analysis }\left(\mathbf{m m}^{3}\right)\end{array} & \begin{array}{c}\left(\mathbf{V}_{/} / \mathbf{V}\right) \\ (\%)\end{array} & \begin{array}{c}(\mathbf{\%}) \\ (\%)\end{array} \\ 10 \mathrm{Fe} & - & - & - & - & - & - \\ 35 \mathrm{Fe} & 2290 & 0.007365053 & 0.000402026 & 0.372379917 & 1.98 & 5.5 \\ 60 \mathrm{Fe} & 1329 & 0.014999003 & 0.009793345 & 0.371952643 & 4.03 & 65\end{array}$

Note: $\mathrm{V}$ : volume of analysis, $\mathrm{V}_{\mathrm{I}}$ : volume of intermetallics, $\mathrm{V}_{\mathrm{L}}$ : volume of the largest intermetallics

half. The formation of huge $\beta$-Fe intermetallics in the $60 \mathrm{Fe}$ specimen leads to the volume increase, which is mainly due to the impingement and branching during the $\beta$-Fe growth process.

Figure 5 shows the three largest intermetallics in the $35 \mathrm{Fe}$ specimen, and the characteristic parameters are shown in Table 4. It can be seen that the size of $\beta$-Fe decreases with the decrease of volume. However, the $3 \mathrm{D}$ morphology of the $3-\beta-\mathrm{Fe}$ is very similar and of very complex shape, and the sphericity values are very low. It is obvious that the impingement happens during their growth ${ }^{[1]}$. As shown in Fig. 5(b) and (c), the shape of $\beta$-Fe intermetallics in the frame is typical " $U$ " shape, which is the interaction of growth of $\alpha-\mathrm{Al}$ dendritic and the intermetallics.

When the Fe content is $0.35 \mathrm{wt} . \%, \beta$-Fe intermetallics is mainly formed during $\mathrm{Al}-\mathrm{Si}-(\beta-\mathrm{Fe})$ ternary eutectic reaction.

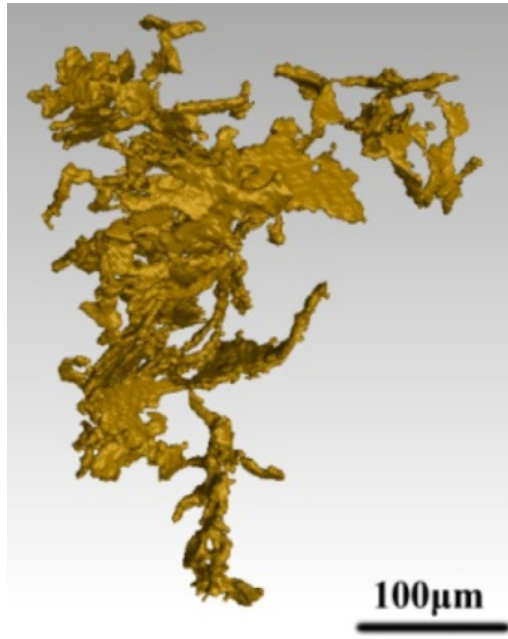

(a) $1-\beta-F e$

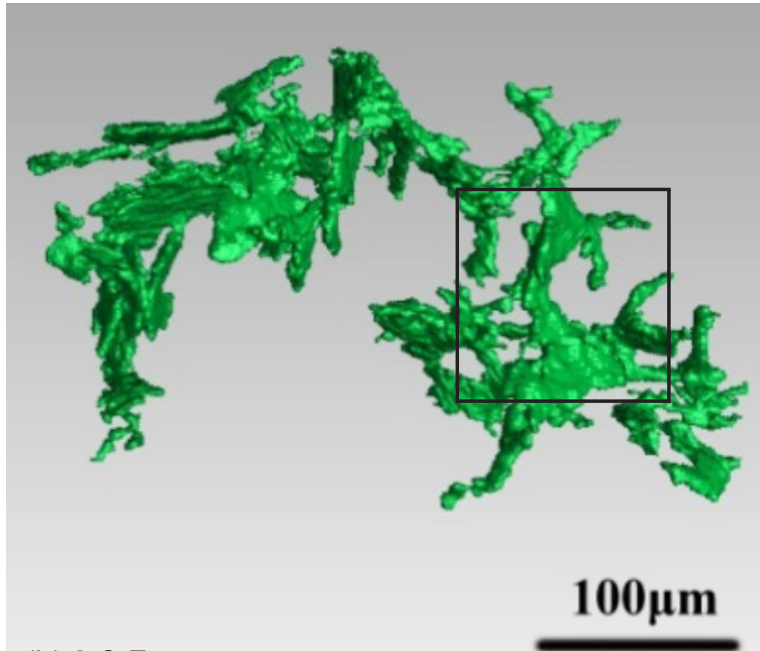

(b) $2-\beta-F e$

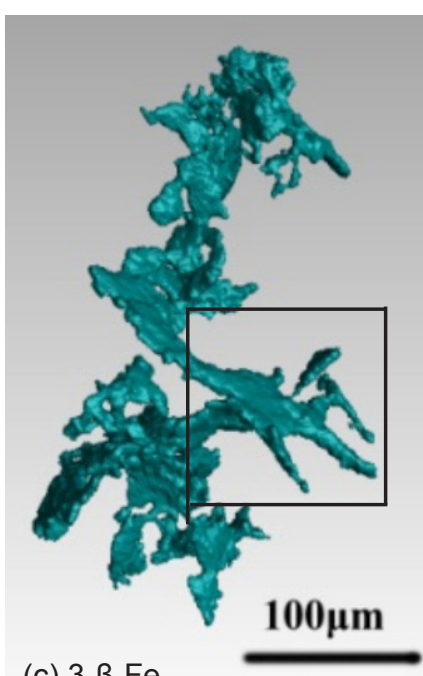

(c) $3-\beta-\mathrm{Fe}$

Fig. 5: Three largest $\beta-\mathrm{Fe}$ intermetallics in $35 \mathrm{Fe}$ specimen 
Table 4: Characterization parameters of $\beta$-Fe in Fig. 5

$\begin{array}{cccc}\text { Mark } & \text { Size }\left(\mathrm{mm}^{3}\right) & \text { Volume }\left(\mathrm{mm}^{3}\right) & \text { Surface area }\left(\mathrm{mm}^{2}\right) \\ 1-\beta-\mathrm{Fe} & 0.375 \times 0.205 \times 0.356 & 0.000402026 & 0.333438009 \\ 2-\beta-\mathrm{Fe} & 0.302 \times 0.251 \times 0.190 & 0.000202695 & 0.178426012 \\ 3-\beta-\mathrm{Fe} & 0.215 \times 0.156 \times 0.197 & 0.000131294 & 0.111306004\end{array}$

At the beginning of the reaction, the solid fraction is high and the $\alpha$-Al dendritic skeleton has formed. Therefore, $\beta$-Fe can only nucleate and grow in the residual liquid phase among $\alpha$-Al dendrites. Since the residual liquid region among the $\alpha-\mathrm{Al}$ dendrites has a tortuous shape, the large volume $\beta$-Fe also has a similar shape.

Figure 6 shows the three largest intermetallics in the $60 \mathrm{Fe}$ specimen, and the characteristic parameters are shown in Table 5. Looking at the volume, the volume of the largest $\beta-\mathrm{Fe}$ is much more than other intermetallics. The 1- $\beta$-Fe in Fig. 6(a) accounts for $65 \%$ of the total volume, and its morphology is very complex and is of low sphericity value 0.03 . The $3 \mathrm{D}$ morphology of 2- $\beta$ $\mathrm{Fe}$ and $3-\beta-\mathrm{Fe}$ is close. Compared with the $35 \mathrm{Fe}$ specimen, the large volume $\beta$-Fe in the $60 \mathrm{Fe}$ specimen is relatively compact and the flake feature is very obvious.

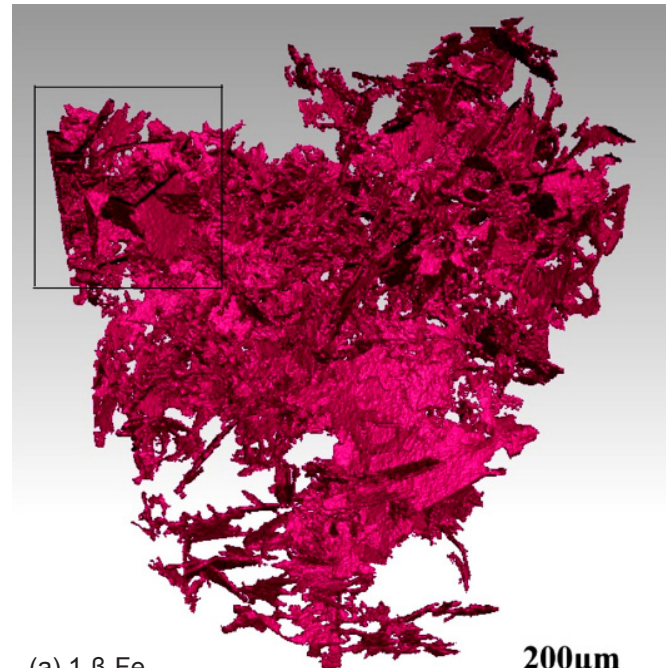

(a) $1-\beta-\mathrm{Fe}$

$200 \mu \mathrm{m}$

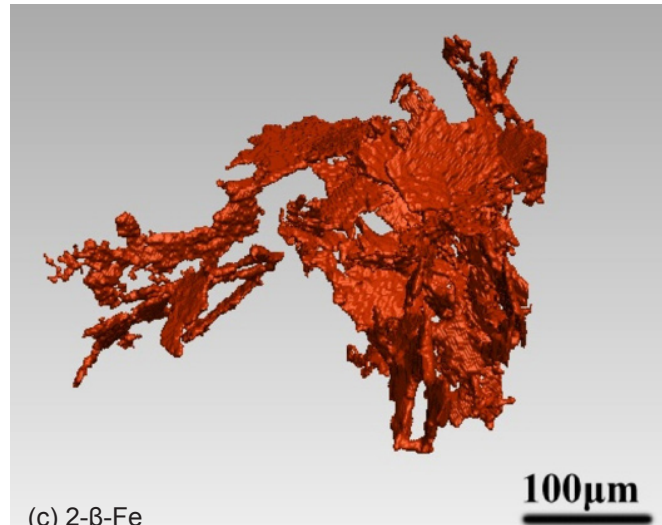

From Fig. 6(a), it is found that the morphology of $1-\beta-\mathrm{Fe}$ is a flaky network, which is considered to be formed by impingement of $\beta$-Fe intermetallics during growth ${ }^{[1]}$. The hollow $\beta-\mathrm{Fe}$ intermetallics indicate that the intermetallics grow across the $\alpha-\mathrm{Al}$ dendrites when the Fe content is high, which is consistent with the results of other studies ${ }^{[1,3]}$. Figure $6(\mathrm{~b})$ is a cross-sectional view of $1-\beta-\mathrm{Fe}$, and it can be clearly seen that the branching between $\beta-\mathrm{Fe}$ in the $60 \mathrm{Fe}$ specimen is different from that in the $35 \mathrm{Fe}$ specimen. From the morphology of $\beta-\mathrm{Fe}$ in region $\mathrm{A}$, it is known that the branches are due to the branching of $\beta-\mathrm{Fe}^{[1]}$, namely the $\mathrm{Fe}$ atoms in the liquid phase diffuse onto the surface of the existing coarse $\beta$-Fe, and nucleate and grow, forming new branches. From the morphology of $\beta$-Fe in region $\mathrm{B}$, the angle between the adjacent $\beta$-Fe is $90^{\circ}$ and the thickness is equivalent, it is considered that they impinged during the growth process.
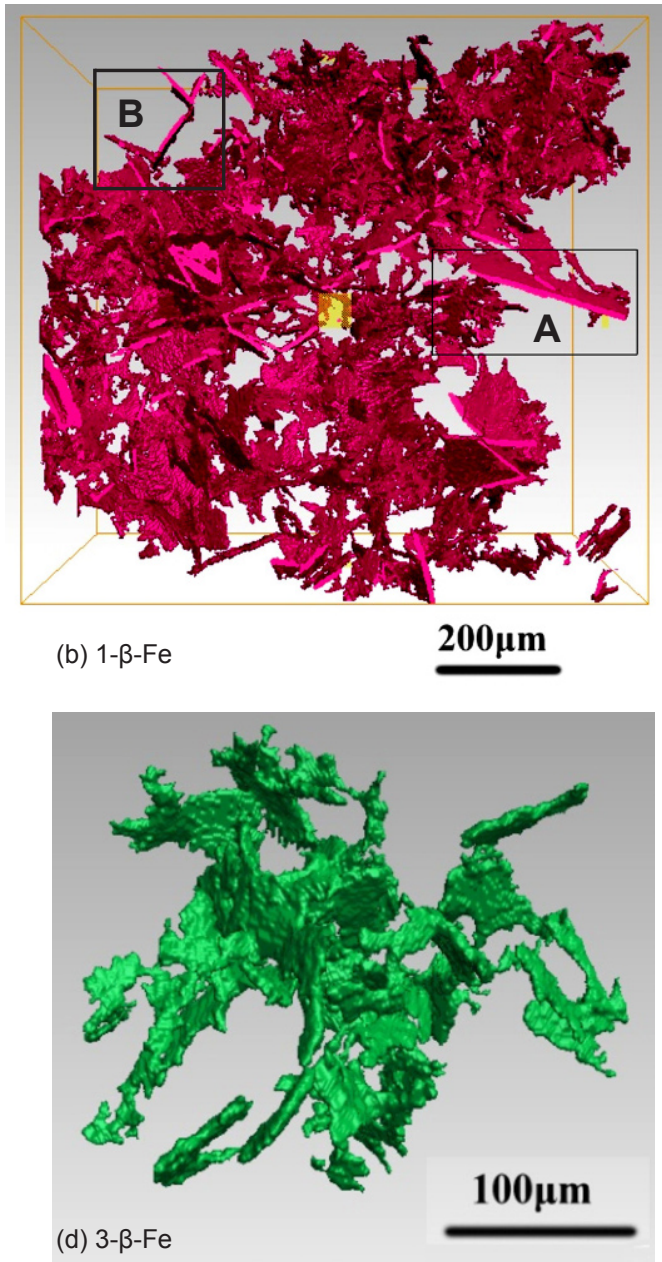

Fig. 6: Three largest $\beta-F e$ intermetallics in $60 \mathrm{Fe}$ specimen 
Table 5: Characterization parameters of $\beta-F e$ in Fig. 6

\begin{tabular}{ccccc} 
Mark & Size $\left(\mathrm{mm}^{3}\right)$ & Volume $\left(\mathrm{mm}^{3}\right)$ & Surface area $\left(\mathrm{mm}^{2}\right)$ & Sphericity \\
\hline $1-\beta-\mathrm{Fe}$ & $0.797 \times 0.797 \times 0.747$ & 0.009793345 & 8.487480164 & 0.03 \\
$2-\beta-\mathrm{Fe}$ & $0.318 \times 0.322 \times 0.311$ & 0.000463323 & 0.417250007 & 0.07 \\
$3-\beta-\mathrm{Fe}$ & $0.257 \times 0.274 \times 0.258$ & 0.000200829 & 0.189387992 & 0.09
\end{tabular}

The above results have shown that the largest $\beta$-Fe in the $60 \mathrm{Fe}$ specimen is very complex, which is mainly related to the formation of $\beta-\mathrm{Fe}$. From the solidification sequence of $60 \mathrm{Fe}$ in the Fig. 2(c), it can be seen that when the Fe content is 0.60 wt.\%, $\beta$-Fe intermetallics form due to the binary eutectic reaction. During the reaction with high temperature, the diffusion of $\mathrm{Fe}$ atoms is high, which is in favor of $\beta-F e$ growth. In addition, the reaction starts at the solid fraction of 0.4 , at which point the $\alpha-\mathrm{Al}$ dendritic skeleton has not yet formed. Therefore, the liquid spacing is large and connected. The $\beta$-Fe intermetallics growing in the liquid are prone to impinge, forming a flake network. Furthermore, the surface of eutectic $\beta$-Fe is very large, which provides a good nucleation substrate for the subsequent ternary eutectic $\beta$-Fe. The ternary eutectic $\beta$-Fe does not undergo homogeneous nucleation and attach to binary eutectic B-Fe, forming a new branch. The above reasons lead to large $\beta$-Fe flake network with extremely complex morphology in the $60 \mathrm{Fe}$ specimen. The network obviously damages the integrity of alloy matrix, and hence decreases the alloy mechanical properties.

\subsection{Effect of Fe-rich intermetallics on micropores}

\subsubsection{Contents of micropores}

Figure 7 shows the percentage of micropores in the wedge castings with different $\mathrm{Fe}$ contents. The porosity of $35 \mathrm{Fe}$ alloy is the lowest, while the porosity of $60 \mathrm{Fe}$ alloy is the highest. This is mainly because of different Fe content in the alloys and their solidification sequence. The second stage of the $10 \mathrm{Fe}$

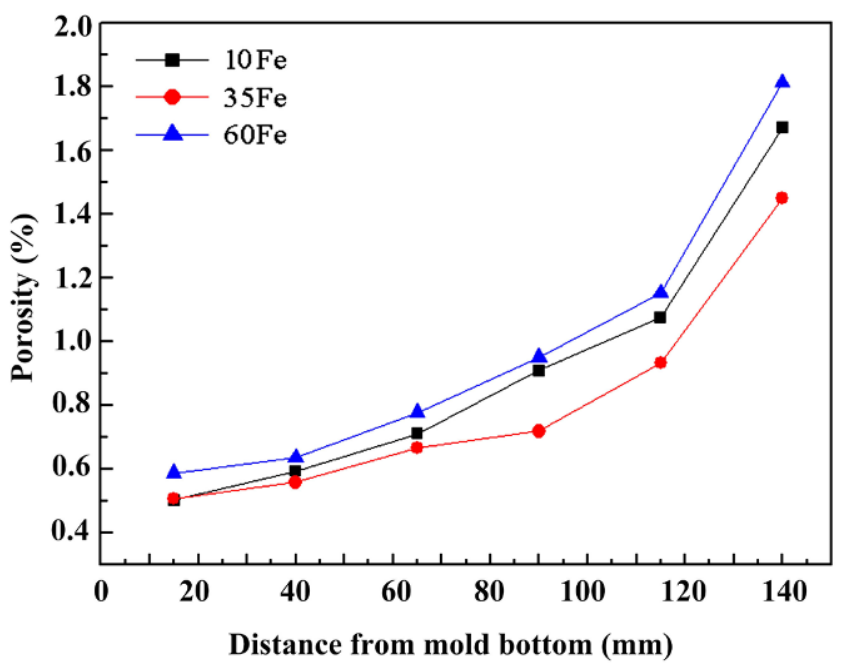

Fig. 7: Porosity of Al-6Si-xFe alloy wedge castings alloy solidification is Al-Si binary eutectic transformation, the transformation duration was long, and the ternary eutectic reaction starts at solid fraction of 0.9 . The liquid phase remains in the isolated region, so it is difficult to feed shrinkage, forming micropores. In contrast, the second transformation of the $35 \mathrm{Fe}$ alloy solidification is binary eutectic reaction, in which the duration is very short, so the ternary eutectic reaction starts at the solid fraction 0.57 . At the time, the solid skeleton is not formed, and interdendritic feeding is sufficient for preventing the formation of porosity. As a result, the porosity content in the $35 \mathrm{Fe}$ is the lowest. In the $60 \mathrm{Fe}$ alloy, the coarse $\beta$-Fe formed during binary eutectic transformation prevents the feeding flow, resulting in the most porosity contents.

\subsubsection{D morphology of micropores}

Since the specimens of the 3D X-ray computed tomography are relatively small, micropores are not necessarily present in the scanning domain. The micropores in the $60 \mathrm{Fe}$ specimen are shown in Fig. 8, and the characteristic parameters of the micropores are shown in Table 6 .

It can be seen from Table 6 that these three micropores are large in size and have a very complex morphology, and there are many pits on the surface of micropores, which are traces of the interaction between micropores and dendritic arms. Therefore, they are shrink-induced pores.

To study the influence of $\beta$-Fe on the micropores, the $1 \#$ pore and its surrounding $\beta$-Fe were resconstructed, as shown in Fig. 9. In Fig. 9, it is obvious that the micropores are in contact with many $\beta$-Fe, indicating that the micropores are formed under the

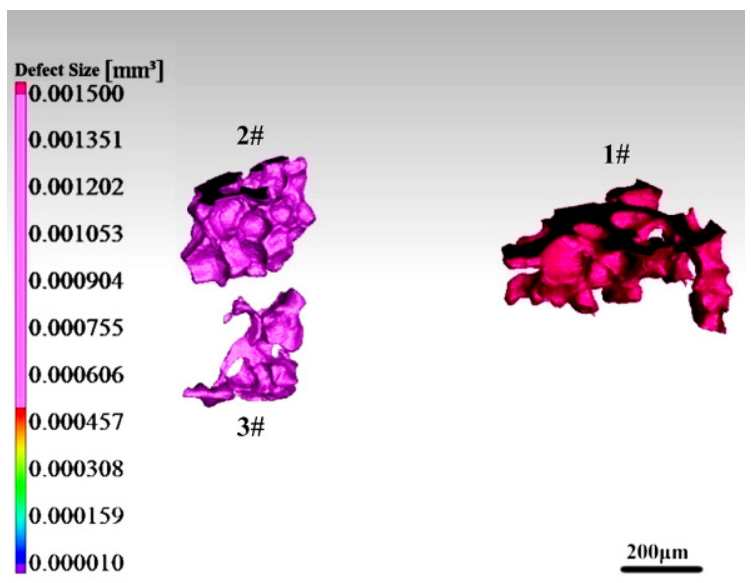

Fig. 8: Morphology of micropores in 60Fe specimen 
Table 6: Characteristic parameters of micropores in Fig. 8

$\begin{array}{ccccc}\text { No. } & \text { Size }\left(\mathrm{mm}^{3}\right) & \text { Volume }\left(\mathrm{mm}^{3}\right) & \text { Surface area }\left(\mathrm{mm}^{2}\right) & \text { Sphericity } \\ 1 \# & 0.302 \times 0.295 \times 0.222 & 0.001696085 & 0.347328126 & 0.2 \\ 2 \# & 0.238 \times 0.116 \times 0.168 & 0.001025717 & 0.176477790 & 0.28 \\ 3 \# & 0.236 \times 0.096 \times 0.230 & 0.000565093 & 0.135722905 & 0.24\end{array}$

action of multiple $\beta$-Fe. On the one hand, with the solidification of the alloy, the hydrogen concentration in the liquid phase became higher. Because the interface energy between $\beta$-Fe and hydrogen is low, $\beta-\mathrm{Fe}$ can act as the substrate of pore nucleation. On the other hand, when the Fe content is $0.6 w t . \%, \beta-\mathrm{Fe}$ is a complex flaky network, and the flow and shrinkage of the molten aluminum are blocked, resulting in a serious decrease in permeability and hence the local feeding and pressure. These caused the formation of pores. In addition, due to the interaction of micropores with the existing solid phase, micropores would contact and interact with $\alpha-\mathrm{Al}$ and $\beta$-Fe during the growth process. Therefore, it was found that $\beta-\mathrm{Fe}$ intermetallics are at the boundary of the micropores, as shown in Fig. 9.

\section{Conclusions}

(1) With increasing the Fe content, the volume fraction of $\beta$-Fe intermetallics in Al-6Si alloy increases, and the branching phenomenon is more obvious during the $\beta$-Fe growth process. In addition, the volume of the largest size $\beta$-Fe intermetallics in the Al-6Si alloy increases and its 3D morphology is rather complex.

(2) When the Fe content is low $(10 \mathrm{Fe})$, the Fe-rich intermetallics are small ternary eutectic $\beta$-Fe intermetallics; when the Fe content is high $(35 \mathrm{Fe}$ and $60 \mathrm{Fe})$, the Fe-rich intermetallics are dominated by coarse binary eutectic, and impingement and branching happen as they grow up, forming huge $\beta$-Fe flake networks.

(3) The micropores are mainly shrinkage pores in the Al-6Si$x \mathrm{Fe}$ alloy. When the Fe content is $0.60 \mathrm{wt} . \%$, the binary eutectic $\alpha$-Fe forms in the early solidification stage, which prevents the feeding flow and decreases permeability. Furthermore, the coarse $\beta-\mathrm{Fe}$ can act as the nucleation substrate for the pores. Both increase the content of micropores in the alloy.

\section{References}

[1] Puncreobutr C, Phillion A B, Fife J L, et al. In situ quantification of the nucleation and growth of Fe-rich intermetallics during $\mathrm{Al}$ alloy solidification. Acta Materialia, 2014, 79: 292-303.

[2] Wang J, Lee P D, Hamilton R W, et al. The kinetics of Fe-rich

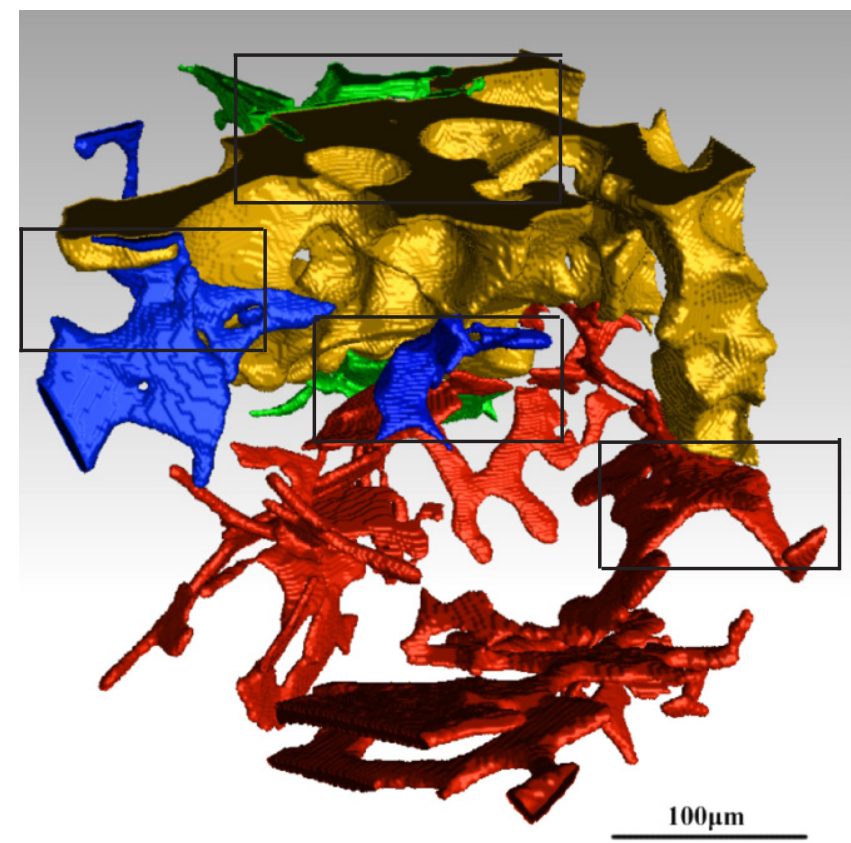

Fig. 9: Largest pore and nearby $\beta-\mathrm{Fe}$ in $60 \mathrm{Fe}$ CT specimen

intermetallic formation in aluminium alloys: In situ observation. Scripta Materialia, 2009, 60(7): 516-519.

[3] Terzi S, Taylor J A, Cho Y H, et al. In situ study of nucleation and growth of the irregular $\alpha-\mathrm{Al} / \mathrm{\beta}-\mathrm{Al}{ }_{5} \mathrm{FeSi}$ eutectic by $3-\mathrm{D}$ synchrotron $\mathrm{X}$-ray microtomography. Acta Materialia, 2010, 58(16): 5370-5380.

[4] McDonald S D, Dahle A K, Taylor J A, et al. Modification-related porosity formation in hypoeutectic aluminum-silicon alloys. Metallurgical and Materials Transactions B, 2004, 35(6): 1097-1106.

[5] Lu L, Nogita K, McDonald S D, et al. Eutectic solidification and its role in casting porosity formation. JOM, 2004, 56(11): 52-58.

[6] Tiedje N S, Taylor J A, Easton M A. Feeding and distribution of porosity in cast Al-Si alloys as function of alloy composition and modification. Metallurgical and Materials Transactions A, 2012, 43(12): 4846-4858.

[7] Tiedje N S, Taylor J A, Easton M A. A new multi-zone model for porosity distribution in Al-Si alloy castings. Acta Materialia, 2013, 61(8): 30373049.

[8] Dinnis C M, Taylor J A, Dahle A K. Iron-related porosity in Al-Si-(Cu) foundry alloys. Materials Science and Engineering: A, 2006, 425(1): 286-296.

[9] Moustafa M A. Effect of iron content on the formation of $\beta-\mathrm{Al}_{5} \mathrm{FeSi}$ and porosity in Al-Si eutectic alloys. Journal of Materials Processing Technology, 2009, 209(1): 605-610. 